\title{
Research on Innovation Mode of Human Resource Management of Shared Platform Against the Background of Digital Economy
}

\author{
Shan $\mathrm{He}^{1, *}$ Yutong Wang ${ }^{1}$ Qiong Xiao ${ }^{1} \mathrm{Ke} \mathrm{Xia}^{1}$ \\ ${ }^{1}$ School of Business, Jiangxi Normal University, Nanchang, Jiangxi 330000, China \\ *Corresponding author.Email: hsjc9466@163.com
}

\begin{abstract}
As the global economy enters the digital age, the popularization of big data and the Internet, and the continuous breakthroughs in new technologies such as artificial intelligence and blockchain have provided important support for the development of platform-based enterprises. Platform-based enterprises have entered a period of rapid development and urgently need to innovate a new model of human resource management. In this context, this paper takes the sharing platform Didi as the research object. Based on grounded theory and coding technology, six relationship categories are condensed and refined from second-hand data, namely management module upgrade, market-oriented configuration, digital technology innovation, network technology connection, demandoriented drive, human capital sharing, and the core areas of platform management, information technology, and affiliated employees have constructed an innovative model of human resource management under the background of the digital economy. This paper not only helps to break through the limitations of the existing sharing platform enterprise human resource management mode, but also has reference value for the transformation of traditional enterprise human resource management mode to digital.
\end{abstract}

Keywords: Digital economy, Sharing platform, Human resource management, Grounded theory.

\section{INTRODUCTION}

With the popularization of big data, 5G networks, and artificial intelligence, the rapid development of the digital economy has ushered in new opportunities and challenges for the development of platform-based enterprises. my country also attaches great importance to the digital economy to promote the transformation of national strategic emerging industries, and regards the digital economy as a new engine to enhance the country's comprehensive strength [1]. As a new economic model, sharing economy optimizes tangible and intangible resources and integrates idle resources with the help of Internet economy through sharing platforms, which has attracted attention from all walks of life (ShuPei Xu, 2020) [2]. The human resource management model under the sharing economy is also gradually changing. Employees such as Didi drivers, Uber drivers, and Airbnb hosts of sharing platform companies have significant "sharing" characteristics.
As a typical sharing platform company under the Internet and the sharing economy, Didi has further expanded its scale after Uber entered China and merged with Didi, enjoying huge dividends when the sharing economy is developing rapidly. According to data analysis of the online car-hailing industry, the number of monthly active users of the Didi Travel app exceeded 54 million in 2020. With a high market share, Didi accidents are frequent, and corporate employee management problems are gradually exposed.

In the context of the digital economy, market competition has intensified, and market competition is the competition of talents. Human resource management, as an important production factor and core resource of an enterprise, as one of the core management of an enterprise, should adapt to the rapid changes in the external environment and internal business, to make innovative changes that adapt to the background of the digital economy to accelerate the renewal and transformation of existing business models. With the continuous 
development and innovation of digital technology, the relationship between enterprises and employees has also changed. How to better conduct human resource management in this context, and how to build a shared platform enterprise's human resource management innovation model is worth studying. The current research on Didi platform management models is mostly qualitative analysis from a single perspective such as performance management and social responsibility. In the existing literature, there are few studies on the human resource innovation model proposed by the sharing platform under the background of the digital economy.

This article will take the Didi sharing platform as the research object, and build an innovative model of human resource management on the sharing platform by using grounded theory. Based on the innovative model summarized, it provides assistance for companies to combine human resource management with digitalization and provides practical guidance for the development of human resource management.

\section{LITERATURE REVIEW}

\subsection{Digital Economy}

The concept of "digital economy" was first proposed by Canadian scholar Don Tapscott in 1996. As the government reports increasingly emphasized "building the advantages of the digital economy", research on the digital economy has gradually became the focus of attention of scholars. At present, the research of digital economy at home and abroad has not reached a unified consensus. Shuaitao Jiao and Qiubi Sun (2021) believe that the commonality of these studies is that the digital economy is a new economic form brought about by information technology (or digital technology) and informatization[3]. With the accelerated development of the digital economy, the digital platform and digital information are changing people's basic lives. "Everyone is contributing data and everyone is enjoying data." In the future, efforts should be made to make the digital economy and digital technology better serve people and improve their lives (Zhenguo Ling, 2021) [4].

\subsection{Sharing Economy Platform}

With the development of the Internet economy and the continuous changes in the environment, corporate organizational structures are gradually changing towards flattening. More and more traditional enterprises have begun to transform to platform-based enterprises, and many sharing platforms characterized by the sharing economy have also begun to develop rapidly.

Felson and Spaeth (1978) first proposed the concept of Sharing Economy based on the theory of human ecology. They expressed this as sharing with relatives and friends in terms of food, clothing, housing and transportation [5]. Kuang Tang and Yanjun Li (2016) believe that the sharing economy is to make full use of the private idle resources outside the traditional market economy with the help of the sharing economy platform. Individuals can share their own resources, and enterprises can effectively allocate idle resources to improve resource utilization [6].

The sharing economy platform is a platform company that integrates a large number of demandside and supply-side resources. The platform does not directly own its assets, but obtains commissions through transactions between the two parties. The sharing economy platform maximizes the benefits of both parties by optimally matching the demand side and the supply side.

\subsection{Shared Human Resource Management}

After the rapid development of shared platform enterprises, many scholars have explored human resource management under the shared platform and compared with traditional human resource management.

Chaomin Gao (2015) referred to shared human resource management as semi-contractual human resource management, and explored shared human resource management from the aspects of recruitment management, training, performance, salary and welfare, and employee relations, and obtained the characteristics of semi-contractual human resource management: the assessment of moral quality should be stricter; the use of the Internet for training and assessment, etc [7].

Xiaodong Yu et al. (2016) referred to the human resource management under the shared platform as a semi-affiliated personnel management model, taking Didi Chu's behavior as an example, and analyzed the characteristics of shared human resource management from three aspects: driver selection, assessment, incentives and punishment, and compared with traditional human resource management. It is concluded that Didi Chuxing conducts assessment based on passenger 
satisfaction, flexible working hours, effective incentives provided, etc [8].

\subsection{Shared Employees}

Shared employees, also known as "shared labor", refers to the adjustment of labor shortage or surplus between different labor subjects in special periods, which originates from the "work sharing" implemented in the developed countries of western market economy. Its core is to reduce layoffs by reducing per capita working hours, (European Commission, 2010) which was widely promoted during the Great Depression and the financial crisis. (Ghosheh \& Messenger,2013) It is also used as an important policy tool to limit or avoid job loss and support enterprises to retain their labor force during economic downturn. At the beginning of 2020, under the continuous impact of the new crown pneumonia epidemic, some small and mediumsized enterprises that are temporarily unable to resume work have to pay their employees basic wages, which is under great pressure. At the same time, due to the soaring demand for online shopping, a large number of vacancies have appeared in online retail companies' store employees and distribution brother positions, so a new employment model of "shared employees" has emerged.

\section{RESEARCH DESIGN AND METHODS}

\subsection{Research Methods}

This research explores the innovative model of human resource management on the sharing platform in the context of the digital economy. With the acceleration of the digitalization process, the number of platform-based companies has gradually increased and their maturity has increased. Different platform-based companies have different influencing factors in human resource management. The single case study method is conducive to indepth understanding of the characteristics of corporate human resource management and intensification of new things. Therefore, this article takes Didi as the research object of a typical sharing platform company to explore. And using grounded theory and coding technology, directly based on the most intuitive secondary data, the network comments and literature reports reflecting the human resource management of Didi are directly coded with open code, spindle code and selective code, and finally build a shared platform for human resource management innovation mode.

\subsection{Case Selection}

This study adopts a single case study method and selects a typical platform-based companyDidi as the research object. There are three reasons for choosing Didi to discuss and construct an innovative model of human resource management for platform-based companies. The first, Didi, as a one-stop travel platform covering multiple businesses, is a typical representative of the sharing economy in China. The second, Didi's employee management methods are very different from those of other traditional companies, and have a strong reference to other platform-based companies. The third, Didi has more than 400 million users. However, in recent years, Didi accidents have occurred frequently, and the issues of corporate employee management and employee rights protection have attracted attention.

\subsection{Sample Data Collection}

In order to collect a more comprehensive reflection of the current situation of human resource management of Didi secondary data, this article adopts three channels: literature, Zhihu, and Baidu. The summary of the existing literature's description of the status quo of Didi's corporate management, and the effective extraction of relevant reports, comments and posts about Didi enterprises on the two authoritative media platforms of Zhihu and Baidu are served as a data support for the status quo of human resource management of Didi platform enterprises. Using grounded theoretical methods to summarize and analyze, and propose an innovative model of human resource management for platform-based enterprises under the background of digital economy.

\section{GROUNDED THEORY DESIGN}

\subsection{Open Coding}

Through the collection and sentence-bysentence analysis of second-hand data, this article first cuts out the original data, then extracts related concepts according to the original data. Finally, according to the rules of the grounded theory and summed up the coding technology of related concept induction 16 main categories.

In order to better express the meaning of the original materials, this article carries out detailed coding in accordance with "source-serial number- 
paragraph-sentence number". The codes A, B, and $\mathrm{C}$ in the text are document code, Zhihu code, and Baidu code respectively. This article will illustrate the operation steps of extracting concepts by example: For example, the original data code "B09-05-03" represents the 03 sentence of the 05th paragraph of the 09th valid data searched from Zhihu. Some open codes are shown in "Table 1".

Table 1. Open coding (partial data)

Welfare treatment, salary incentives, targeted subsidies, determined salary, driver salary, subsidy income, salary guarantee, income tax, two-way pricing, price opacity, maximum benefit, employee income, income shrinkage, high deduction, insurance benefits, family benefits , Medical reimbursement

Quality assessment, ability test, recruitment selection, recruitment selection, compliance regulations, qualification review, extended recruitment process, recruitment threshold, driver recruitment, simple conditions, driver materials, entry threshold, online recruitment, use of rental companies, review

Personnel selection

Effective allocation, integration of service resources, coordination of resources, restricted use, adaptation to local conditions, resource integration, market cooperation, integration of idle resources, resource sharing, provision of idle resources, staff allocation, service sub-system, priority allocation, orders and distance

Service attitude, car environment, user needs, user experience, meeting customer needs, service quality, reducing refusal behavior, improving user experience, technical level, professionalism, complaint mechanism, unstable income, good attitude

Artificial intelligence, "Internet +", big data technology, blockchain technology, employee digital ID, digital measurement indicators, technical precision, drive innovation, data drive, digital economy

Digital application

Mass data, computer algorithms, intelligent management, technology management, data analysis, management informationization, intelligent development, big data management, accurate recording, establishment of performance files, evaluation and statistical analysis, data technology, Internet environment, technology leadership, Dimi System, platform dispatch

Application platform, work status upload, information timeliness, platform connection, communication media, incoming calls, navigation and positioning, online platform, online agreement, network platform management, collective collaboration, collaborative complementarity, relying on the Internet, third-party settlement system

Internet technology, effective monitoring, work networking, management information system, Internet information, Internet application, public security system networking, platform customer service system, security technology, mutual benefit network law, website technology, integrated website, network platform, information management, relationship maintenance

Rewarding drivers, knowledge and skills, self-worth, employee promotion, adapting to market needs, being satisfied, self-interest driven, value creation, strong personalization, high independence, inability to improve, no guarantee, income and effort, inequity, etc.

Free time, part-time driver, idle time, leaving the car at the time you want, no mandatory requirements, flexible employment methods, strong autonomy, flexibility, no need to follow cumbersome procedures, flexible working hours, task fragmentation, process autonomy, social employment, flexible labor

\subsection{Spindle Coding}

In this paper, 16 main categories are further summarized and refined, and six relationship categories are obtained: management module upgrade, market-oriented allocation, digital technology innovation, network technology connection, demand-oriented drive and human capital sharing. The category and corresponding connotation of the relationship category and the corresponding influence relationship category are shown in "Table 2". 
Table 2. Spindle coding

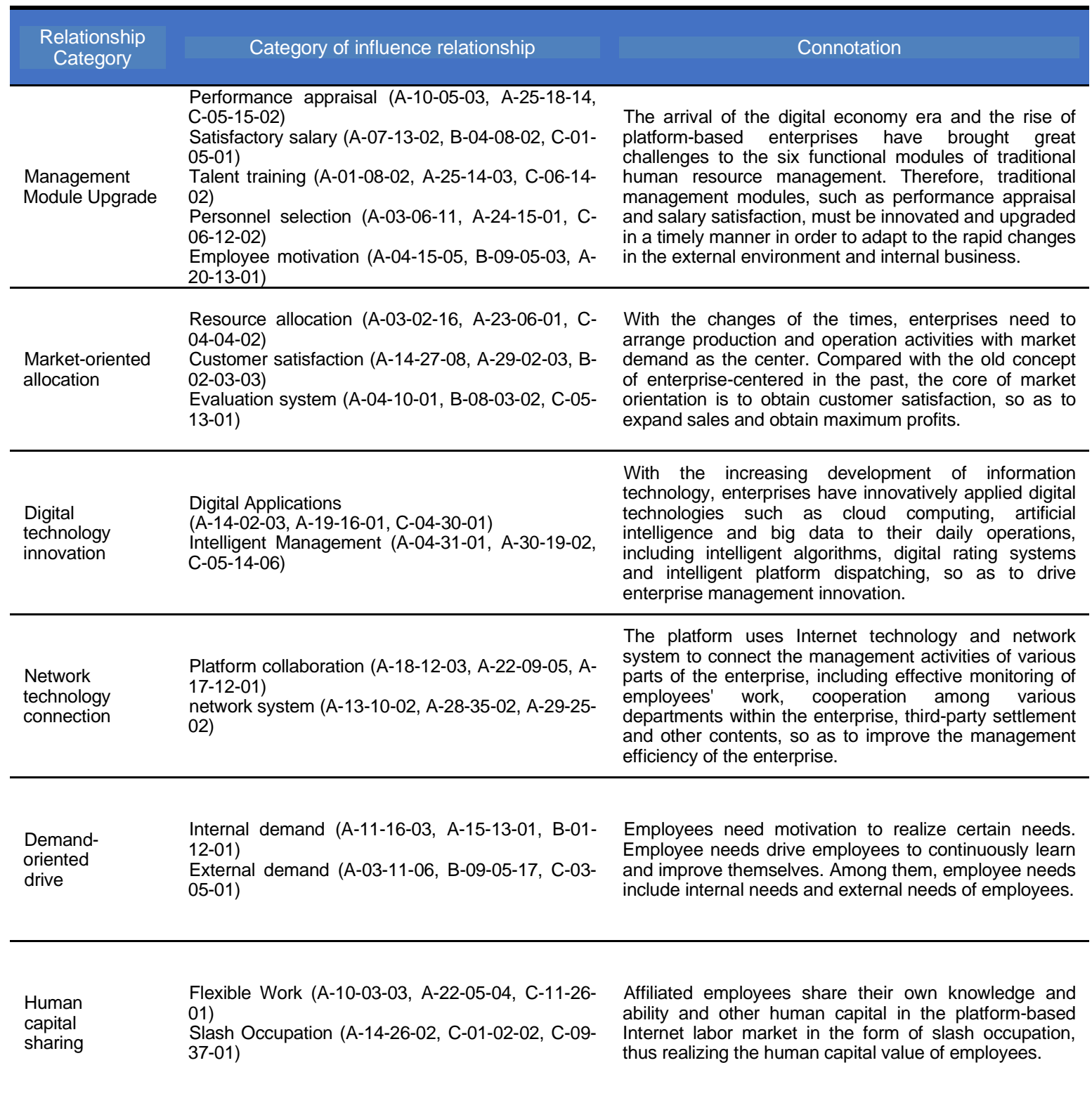

\subsection{Selective Coding}

At this stage, the main axis coding is further integrated and summarized to clarify the overall story line of the data. This article takes the human resource management of the shared platform under the background of the digital economy as the research object. In addition, this paper refines "management module upgrade" and "marketoriented configuration" in "Table 2" into platform management, "digital technology innovation" and "network technology connection" into information technology, and "demand-oriented drive" and "human capital sharing" into affiliated employees, so as to obtain shared platform human resource management innovation Mode ("Figure 1"). 


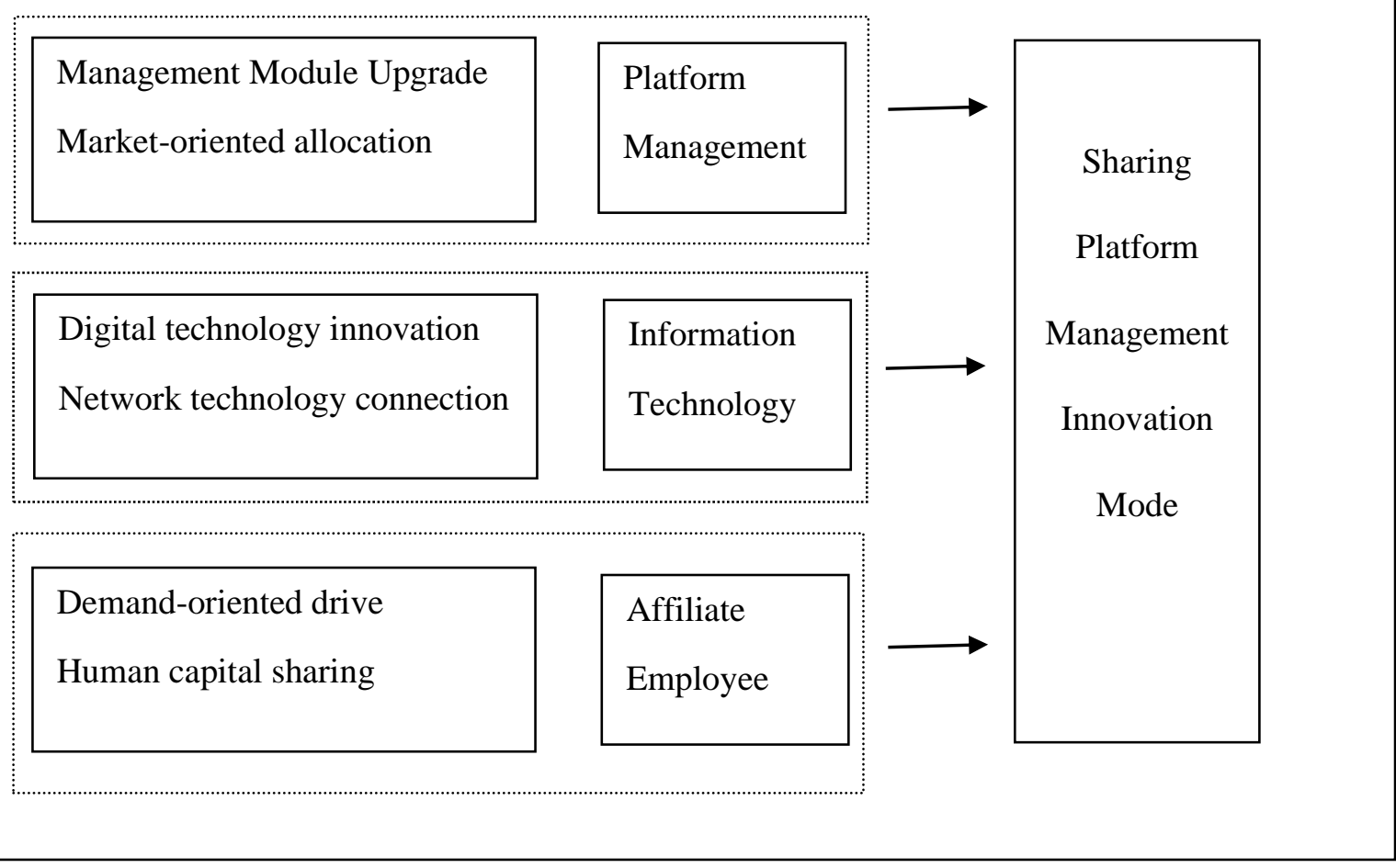

Figure 1 Sharing platform management innovation mode.

\subsection{Description of Innovation Model}

The three core categories derived from the above integration are used as the three dimensions that influence the management innovation model of the sharing platform, and each dimension contains two relationship categories.

\subsubsection{Platform Level}

"Platform management" includes two relationship categories: management module upgrade and market-oriented configuration. The upgrade of the management module reflects the human resource management function of the shared platform. Compared with the traditional six functions of human resource management, in order to adapt to the rapid changes in the internal and external environment of the enterprise, it is necessary to constantly innovate and upgrade. For example, in terms of performance appraisal, Didi drivers can be assessed in conjunction with the market appraisal system to prevent drivers from having poor service attitudes and deliberately swiping orders. In terms of personnel selection, besides the requirements of driving ability, the platform pays more attention to the requirements of quality and morality and pursues customer satisfaction. Compared with the old enterprise- centric concept in the past, Internet digital technology has promoted the dominance of the consumer market. Shared platform enterprises need to control and manage business activities and implement market-oriented configuration centered on market demand. The sharing platform is marketoriented to allocate resources and manpower, focusing on customer needs and customer evaluation, which is also a way of platform management innovation.

\subsubsection{Technical Level}

"Information technology" includes digital technology and network technology. Digital technology provides information media and technical support for the sharing platform, and provides a foundation for the daily operation of the platform through cloud computing, artificial intelligence, big data and other technologies. For example, in terms of performance appraisal, computer algorithms are used to transform objective and quantifiable indicators into data to reduce the influence of human subjective factors. The rapid development of Internet technology has promoted the realization of functions such as online transaction, fast payment, person-to-person positioning and connection, and online evaluation of the sharing platform, helping the sharing 
platform to perform more effective and convenient management. Therefore, the innovation of digital technology and the connection of network technology can provide new and innovative ways for the management of shared platforms.

\subsubsection{Staff Level}

"Affiliated employees" includes two relationship categories: demand-driven and human capital sharing. As a rising employee work model after the emergence of the sharing platform, employees are driven by their own needs, or they need part-time income, or they want to be flexible in their working hours, or they need to continuously improve themselves and gain growth. The knowledge, abilities, skills and other human capital will be shared on the shared platform market to realize the value of their human capital. Therefore, sharing platform companies can innovate platform management based on the needs of their employees and the characteristics of human capital, such as holding company meetings or gatherings at appropriate times to meet their social needs; talented young people with ideas training etc.

\section{RESEARCH CONCLUSIONS AND PROSPECTS}

With the rapid development of information and network technology today, the sharing economy platform has become an important channel for selecting talents and appointing employees, greatly optimizing the allocation of human resources, and helping to solve the long-term and short-term employment problems of enterprises. Under the background of digital economy, the human resource management of shared platform has truly achieved the goal of reducing costs and increasing efficiency. Therefore, it is imperative to explore innovative models of human resource management on shared platforms in the context of the digital economy.

This article takes the sharing platform Didi Company as a case, based on grounded theory and coding technology, extracts concepts from the acquired second-hand data, condenses 16 main categories, 6 relationship categories, and 3 core categories, and summarizes "management module upgrades, market-oriented configuration, digital technology innovation, network technology connection, demand-oriented drive, and human capital sharing" six relationship categories. This paper also constructs the innovation mode of human resource management under the background of digital economy with platform management, information technology and affiliated employees as the core categories.

\subsection{Analysis Conclusion}

After reviewing the development history and current development of Didi's human resource management, this research analyzes and proposes the innovation mode of human resource management in the context of the digital economy from the three aspects of platform management, information technology, and shared employees through the coding process of grounded theory. This article mainly draws the following three conclusions: First, in the context of the digital economy, the platform can innovate the human resource management model through the upgrading of management modules and the adherence to market-oriented configuration. Eligible workers can become shared employees through certain training. Second, in terms of information technology, digital technology innovation and network technology connection should be continuously carried out to implement human resource management with the help of technology and solve the problems existing in human resource management. Third, affiliated employees are used as an important policy tool to limit or avoid job loss and support companies to retain their labor force during the economic downturn. From the two perspectives of demandoriented driving and human capital sharing, it can strengthen employees' work flexibility and ensure that employees' internal and external demands are met. This research has enriched the existing theories in the following aspects. This research integrates and summarizes three core areas, including platform management, information technology and affiliated employees.

This research has certain practical value. This research suggests the specific measures that companies can take in human resource management, especially in platform management, information technology and affiliated employees in the context of the digital economy, and extract six specific paths for human resource management model innovation. In other words, what aspects can companies start from to promote the innovation of shared platform management models.

The conclusions of this study are helpful to promote the understanding and grasp of the innovative model of human resource management on sharing platforms in the context of digital economy. Under the background of the digital 
economy, the Didi Taxi application software has to some extent changed the traditional human resource management mode in which drivers are subject to taxi company policies. It is helpful for the transformation and upgrading of the entire industry and is important for the optimization of the entire industry [8].

Therefore, in the era of rapid development of the digital economy and sharing platforms, it is necessary to grasp the new trends in human resource management in order to gain a competitive advantage and contribute to the rapid development and growth of enterprises

\subsection{Research Limitations and Prospects}

This research also has some research deficiencies, which need to be improved in future research

First, the limitation of the researcher's own data acquisition. College students are unable to directly contact with relevant practitioners and other specific groups that are being researched, which makes this research to collect massive papers and network data for generalization to ensure the validity and reliability of the research results. Future research can make more valuable contributions by identifying the personal, company, and industry-level determinants of the external contacts of executives.

Second, this study uses a single case study, and the research conclusions need to be verified in other cases. Future related research can adopt multiple case studies to enhance the reliability of research results.

Third, this research is limited to proposing theoretical models without further empirical verification. Future research can develop measurement tools for related constructs in the field of shared human resource management, and then conduct empirical research to test related theories.

\section{CONCLUSION}

In the era of digital economy, platform-based enterprises have entered a period of rapid development, and their development is facing new opportunities and challenges. In this context, shared platform enterprises must base themselves on the reality of development, actively adapt to the internal and external competitive markets of digital economy, and innovate the innovative mode of human resource management. Shared platform enterprises make corresponding innovations from platform management, information technology and affiliated employees, break through the limitations of human resource management mode of shared platform enterprises, and expand human resource management channels, thus accelerating the transformation from traditional enterprises to digital business mode. It provides a new perspective for realizing mutual benefit and win-win between enterprises and society.

\section{AUTHORS' CONTRIBUTIONS}

Shan He is responsible for data collection and coding, data analysis, paper editing and modification, Yutong Wang carried out data collection coding, data analysis and paper writing, Qiong Xiao contributed to data collection coding, data analysis and paper writing, and $\mathrm{Ke} \mathrm{Xia}$ participated in the data collection and coding, data analysis and paper writing.

\section{REFERENCES}

[1] Pang Jian, Zhu Xinmin. Development trend of digital economy abroad and national development strategy of digital economy [J]. Scientific and Technological Progress and Countermeasures, 2013, 30 (08): 124-128.

[2] $\mathrm{Xu}$ Shupei. Strategic Change of Resource Provider Management on Internet Sharing Platform [J]. Journal of Guangxi University (Philosophy and Social Sciences Edition), 2020, 42 (06): 100-105.

[3] Jiao Shuaitao, Sun Qiubi.Research on the impact of China's digital economy development on industrial structure upgrading [J]. Industrial Technology and Economy, 2021, 40 (05): 146-154.

[4] Ling Zhenguo. Developing digital economy should be "people-oriented" [N]. People's Political Consultative Conference, 2021-05-06 (007).

[5] FELSONM., SPAETH J. L. Community Structure and Collaborative Consumption[J]. American Behavioral Scientist, 1978, 21(4):614-624.

[6] Tang Li, Li Yanjun, Xu Jingyun. Employment Management of Shared Economy Enterprises and Institutional Innovation of Labor Contract Law [J]. China Labor, 2016 (14): 41-52. 
[7] Gao Chaomin. Research on Semi-contractual Human Resources Management Model under Sharing Economy Model-A Multi-case Study Based on 6 Enterprises [J]. China Human Resources Development, 2015 (23): 16-21.

[8] Yu Xiaodong, Liu Rong, Chen Hao. Exploration of Human Resource Management Mode under the Background of Sharing Economy: Taking Didi Chuxing as an Example [J]. China Human Resources Development, 2016 (06): 6-11+54. 